\title{
Effect of Martensitic Transformation on Elastic Modulus Anisotropy of Ti-6Al-4V Alloy
}

\author{
Zhongxue Feng ${ }^{a}{ }^{\oplus}$, Yingxiang Yang ${ }^{a}$, Zhichao Xü ${ }^{a}$, Qingnan Shi ${ }^{a}$ \\ ${ }^{a}$ School of Materials Science and Engineering, Kunming University of Science and Technology, \\ 650093, Kunming, Yunnan, China
}

Received: March 15, 2018; Revised: May 07, 2018; Accepted: May 16, 2018

\begin{abstract}
The Young's modulus (E), Poisson's ratio (v) and anisotropy parameter $\left(\mathrm{A}_{\mathrm{G}}\right)$ of $\alpha^{\prime}$ phase, which obtained from different solution treatment and water quenching temperature, were investigated using first-principles calculations based on density functional theory (DFT). The calculation results showed that the $\mathrm{Z}$-axis value of the elastic modulus of $\alpha^{\prime}$ phase was higher than that of the $\mathrm{X}$-axis and the Y-axis, indicating the elastic modulus of $\alpha^{\prime}$ phase was anisotropic. It was decreased with increasing the solution treatment and water quenching temperature for the elastic modulus anisotropy of $\alpha^{\prime}$ phase. In order to verify the calculation results, the elastic modulus anisotropy of macroscopic Ti-6Al-4V alloys, which were treated at $850^{\circ} \mathrm{C}, 900^{\circ} \mathrm{C}$ and $950^{\circ} \mathrm{C}$, were tested by the tensile and the compressive experiments. The experimental results showed the same change tendency with the calculation results. It concluded that the elastic modulus anisotropy of macroscopic alloy could be controlled by the elastic modulus anisotropy of $\alpha^{\prime}$ phase.
\end{abstract}

Keywords: $T i-6 A l-4 V$ titanium alloys, martensitic transformation, martensitic nucleation rate.

\section{Introduction}

The microstructure is a fingerprint for the prediction of macroscopic mechanical behavior of the most materials. In typical $\alpha+\beta$ biphase Ti-6Al-4V alloy, controlling microstructure by heat treatment is a common method to produce materials with desired mechanical performance ${ }^{1-5}$. Heat treatment process is a useful method to optimize the microstructure, e.g. optimizing the type and the morphology of phase $e^{6,7}$, controlling the size and the amount of $\alpha$ and $\beta$ phase ${ }^{8-10}$. Rapid quenching leads to a martensitic transformation of $\beta$, resulting in a very fine needle-like microstructure ${ }^{8}$. Unlike the martensitic transformation known in steels, the martensitic transformation in Ti-6Al-4V alloy doesn't lead to strong distortion of the crystal lattice and thus the hardness and strength won't increase remarkably. However, the characteristics of martensite, such as morphology, quantity, size and so on, govern the final mechanical properties of titanium alloy.

In the past decade, in order to obtain precise size of Ti-6Al-4V alloy sheet, it is necessary to carry out repeated rolling of the small pieces of Ti-6Al-4V alloy in different directions rather than continuous rolling as pure titanium due to the Ti-6Al-4V alloy with high strength, high deformation resistance and high resilience ${ }^{11,12}$. Not only that, because the Ti-6Al-4V alloy sheet during the rolling process is easy to form a strong base texture, and the texture evolution increase the deformation resistance and resilience of Ti-6Al-4V alloy sheet seriously ${ }^{13}$. These reasons make controlling sheet size become very difficult, and Ti-6Al-4V alloy sheet shape often appears "ship type" and "wave type" defects. In the previous studies, these works were mainly focused on the influence of texture evolution and strain rate on deformation resistance and resilience, while ignoring the effect of phase transition on the deformation resistance of materials. However, the martensitic transformation process can change the lattice parameter of the phase to alter the anisotropy of the elastic modulus, and thus affecting the deformation resistance and resilience of the material. Therefore, it is necessary to understand the effect of martensitic transformation on the elastic modulus anisotropy after heat treatment in order to find another way to control the precise size of Ti-6Al-4V titanium alloy during rolling deformation and to enhance the hardness, toughness and wear resistance properties of titanium alloy.

In order to develop a better understanding the effect of martensitic transformation on the elastic modulus anisotropy of Ti-6Al-4V alloy during heat treatment process, the tensile properties and compressive properties of Ti-6Al-4V alloy after solution treatment and water quenching at $850^{\circ} \mathrm{C}, 900^{\circ} \mathrm{C}$ and $950^{\circ} \mathrm{C}$ have been tested. The type of phase of Ti-6Al-4V alloy after water quenching from different temperatures was examined by XRD. The Young's modulus (E), Poisson's ratio $(v)$ and anisotropy parameter $\left(\mathrm{A}_{\mathrm{G}}\right)$ of $\alpha^{\prime}$ phase after quenching at different quenching temperatures were investigated using first-principles calculations based on density functional theory (DFT). And it was analyzed that the elastic modulus anisotropy of $\alpha^{\prime}$ phase and the effect on mechanic properties of Ti-6Al-4V alloy. 


\section{Experimental}

\subsection{Establishment of Atomic Model}

The phase transition, $\alpha \rightarrow \beta$, occurs in the $\alpha+\beta$ phase area during the solidification treatment procedure. And the $\beta$ phase transition to $\alpha^{\prime}, \alpha^{\prime \prime}, \omega$ occur during the water quenching process $^{14}$. However, there is only a small amount of $\alpha$ " phase and $\omega$ phase in Ti-6Al-4V alloys during water quenching process. Therefore, the microstructure generally consists of initial $\alpha$ phase and $\alpha^{\prime}$ phase after solution treatment and water quenching in $\alpha+\beta$ phase area. Since the crystal lattice type of $\alpha^{\prime}$ phase is the same as that of $\alpha$ phase, these are both the close-packed hexagonal structure, there are no independent peaks in the XRD diffraction, but the diffraction peak width changes due to the change of the lattice parameter. It is difficult to through the XRD diffraction method to identify the $\alpha$ phase and the $\alpha^{\prime}$ phase. And the lattice parameters of $\alpha$ ' phases will subtle change with the change of $\mathrm{V}$ and $\mathrm{Al}$ contents, it is difficult to accurately determine the lattice parameters of $\alpha^{\prime}$ phase in Ti-6Al-4V alloy macroscopic region by TEM. In this paper, the lattice parameters of $\alpha$ phase were calculated by the XRD pattern of Ti-6Al-4V alloy with different temperature quenching (Fig. 1) and the fitting error was less than $9 \%$. The model builds on $\alpha$ ' phase lattice parameters which equal to the changed lattice parameters. Although the method could not accurately represent the lattice parameters of $\alpha^{\prime}$ phase, but could react to the extent of $\alpha^{\prime}$ phase lattice parameter to a certain extent. The space group type of $\alpha^{\prime}$ phase, the cut-off energy and lattice parameters were shown in Tab.1.

\subsection{Calculation Method}

These calculations were performed using the Cambridge Serial Total Energy Package Code (CASTEP) based on DFT. The Generalized Gradient Approximation (GGA) was employed to evaluate exchange-correlation energy. Ultrasoft pseudopotentials were used for electron-ion interactions. $3 s^{2} 3 p^{6} 3 d^{2} 4 s^{2}$ of Ti as valence electrons were involved in the calculations. The cut-off energy and the $\mathrm{K}$ point network used in these works are shown in Table 1. The cut-off energy was $350 \mathrm{eV}$ and the $\mathrm{K}$-point is $10 \times 10 \times 6$ to ensure the convergence of the system energy and configuration at the plane wave group level. The convergence tolerance was set to force less than $0.01 \mathrm{eV} / \AA$, stress less than $0.02 \mathrm{GPa}$, changed in displacement less than $5 \times 10^{-4} \AA$ and Self-Consistent Field (SCF) less than $1 \times 10^{-6} \mathrm{eV}$.

\subsection{Experimental Method}

Ti-6Al-4V titanium alloy sticks of $10 \mathrm{~mm} \times 10 \mathrm{~mm} \times 100 \mathrm{~mm}$ were used in this study. The element composition of Ti-6Al$4 \mathrm{~V}$ has been tested by X-Ray fluorescence spectrum analysis (XRF). The results were shown in Tab.2. These specimens were separately solution treated at $850^{\circ} \mathrm{C}, 900^{\circ} \mathrm{C}$ and $950^{\circ} \mathrm{C}$ for $1 \mathrm{~h}$ and then quenched in iced water. The optical microstructures were revealed by using the etchant of $\mathrm{HNO}_{3}(5 \%$ vol.) $+\mathrm{HF}$ (10\% vol.) +Water (bal.). X-Ray diffraction using $\mathrm{Cu} \mathrm{K \alpha}$ was performed at $40 \mathrm{KV}-100 \mathrm{~mA}$ to determine the type of phase of these specimens. Tensile tests and compression tests were carried out using a universal mechanical testing machine at room temperatures with an initial strain rate of $0.1 \mathrm{~S}^{-1}$, and the fracture surface was observed by scanning electron microscope (SEM).

\section{Results and Discussion}

\subsection{Microstructure and phase characterization}

Fig. 1 shows the microstructure of Ti-6Al-4V alloy after solution treatment and water quenching at $850^{\circ} \mathrm{C}, 900^{\circ} \mathrm{C}$ and $950^{\circ} \mathrm{C}$. The as-received microstructure of the Ti-6Al-4V alloy consisted of about $96 \%$ primary $\alpha$ phase and $\beta$ phase, and the average diameter of the $\alpha$ phase grains was about $11 \mu \mathrm{m}$, as shown in Fig. 1 (a). The microstructure of the sample, which was solution treatment and water quenching at $850^{\circ} \mathrm{C}$, contained amount of $\alpha$ phase and fine needle-like $\alpha^{\prime}$ phase. The grain boundary of $\alpha$ phase was changed from linear to "zig-zag" and the gap among $\alpha$ phase grains became more broadly. The phase transition, $\beta \rightarrow \alpha$, appeared during the water quenching treatment process and the area fraction of $\alpha$ phase decreased compared the as-received Ti-6Al-4V alloy, as shown in Fig. 1 (b). Fig.1c shows the microstructure of Ti-6Al-4V alloy, which was solution treatment and water quenching at $900^{\circ} \mathrm{C}$. It consisted equiaxed $\alpha$ phase, needle-like $\alpha^{\prime}$ phase and few $\alpha^{\prime \prime}$ phase. The changes of the shape and the area fraction of $\alpha$ phase were observed. The $\alpha$ phase changed from irregularity to equiaxed geometry and the area fraction of $\alpha^{\prime}$ phase increased compared with the microstructure of Ti-6Al-4V alloy treated at $850^{\circ} \mathrm{C}$. In contrast, as shown in Fig. 1 (d), when the sample was treated at $950^{\circ} \mathrm{C}$, the size of $\beta$ phase increase sharply and the diameter of the $\beta$ phase was changed from $11 \mu \mathrm{m}$ to $400 \mu \mathrm{m}$. The matrix was full of $\alpha^{\prime}$ phase and $\alpha^{\prime \prime}$ phase. It concluded that the content of $\alpha^{\prime}$ phase increased with increasing the solution and water quenching temperature.

Fig. 2 shows the XRD profiles of samples, which was solution treatment and water quenching at $850^{\circ} \mathrm{C}, 900^{\circ} \mathrm{C}$ and $950^{\circ} \mathrm{C}$. Since the $\alpha$ phase and $\alpha^{\prime}$ phase had similar lattice constants, only $\alpha$ phase's peaks were observed in all the XRD profiles. There was not obviously difference in angle of diffraction among XRD profiles. Although $\alpha$ " phase existed in the matrix, no separate peaks of $\alpha^{\prime \prime}$ phase were observed in XRD profiles. On the one side, there were few $\alpha$ " phase. On the other side, the three peaks of $\alpha^{\prime \prime}$ phase just located at $40^{\circ}, 41.12^{\circ}$ and $74.6^{\circ}$, it was considered that the $\alpha$ " phase peaks were covered by the remarkable widening peaks in $38.48^{\circ}$ and $40^{\circ}$. Additionally, the width of peaks in $38.48^{\circ}$ and $40^{\circ}$ became widen with increasing the treatment 

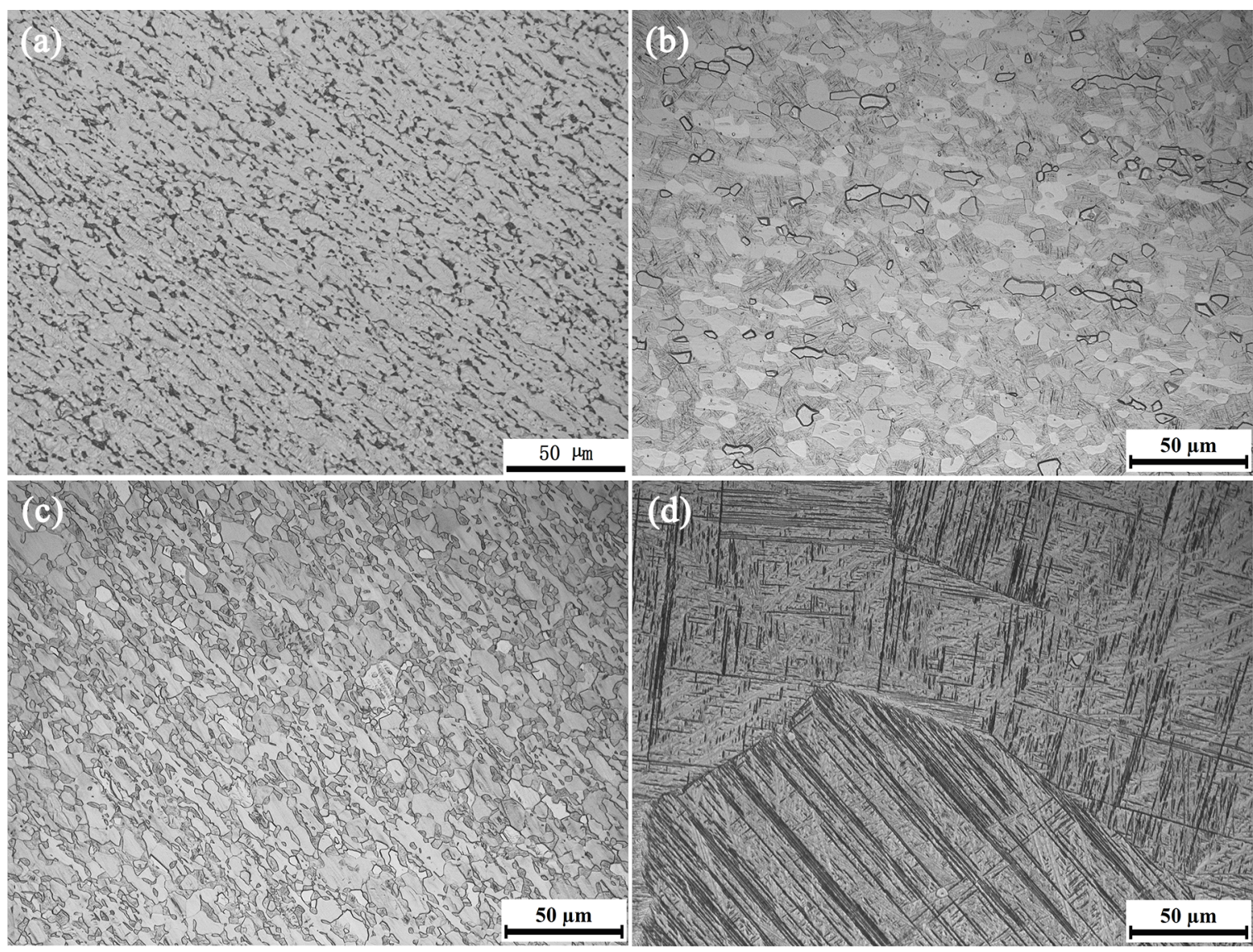

Figure 1. Microstructure of Ti-6Al-4V with different heat treatment temperature: (a) original material; (b) $850^{\circ} \mathrm{C} / 1 \mathrm{~h}+\mathrm{WQ} ;(\mathrm{c})$ $900^{\circ} \mathrm{C} / 1 \mathrm{~h}+\mathrm{WQ}$;(d) $950^{\circ} \mathrm{C} / 1 \mathrm{~h}+\mathrm{WQ}$.

Table 1. The details of the cut-off energy, the k-mesh and the crystallographic data of calculation in this work.

\begin{tabular}{lcccc}
\hline Phase & Cut-off energy $(\mathrm{eV})$ & K-Mesh & Space group & Lattice parameters $(\AA)$ \\
\hline$\alpha^{\prime}\left(850^{\circ} / 1 \mathrm{~h}+\mathrm{WQ}\right)$ & 350 & $10 \times 10 \times 6$ & $\mathrm{P} 63 / \operatorname{mmc}(194)$ & $\mathrm{a}=\mathrm{b}=2.93169, \mathrm{c}=4.68100$ \\
$\alpha^{\prime}\left(900^{\circ} \mathrm{C} / 1 \mathrm{~h}+\mathrm{WQ}\right)$ & 350 & $10 \mathrm{x} 10 \mathrm{x} 6$ & $\mathrm{P} 63 / \operatorname{mmc}(194)$ & $\mathrm{a}=\mathrm{b}=2.94072, \mathrm{c}=4.68559$ \\
$\alpha^{\prime}\left(950^{\circ} \mathrm{C} / 1 \mathrm{~h}+\mathrm{WQ}\right)$ & 350 & $10 \times 10 \times 6$ & $\mathrm{P} 63 / \operatorname{mmc}(194)$ & $\mathrm{a}=\mathrm{b}=2.92678, \mathrm{c}=4.66747$ \\
\hline
\end{tabular}

Table 2. The element contents of Ti-6Al-4V titanium alloys used in this study (mass \%).

\begin{tabular}{lccccccccc}
\hline Alloy & $\mathrm{Ti}$ & $\mathrm{Al}$ & $\mathrm{V}$ & $\mathrm{Fe}$ & $\mathrm{C}$ & $\mathrm{H}$ & $\mathrm{O}$ & $\mathrm{N}$ \\
\hline Ti-6Al-4V & Bal. & 6.45 & 4.21 & 0.20 & 0.032 & 0.015 & 0.115 & 0.0084 \\
\hline
\end{tabular}

temperature from $850^{\circ} \mathrm{C}$ to $900^{\circ} \mathrm{C}$. However, when the Ti$6 \mathrm{Al}-4 \mathrm{~V}$ alloy treated at $950^{\circ} \mathrm{C}$, the width of peaks in $38.48^{\circ}$ and $40^{\circ}$ became narrow compared at $850^{\circ} \mathrm{C}$ and $900^{\circ} \mathrm{C}$. The peak width of the sample treated at $900^{\circ} \mathrm{C}$, in $38.48^{\circ}$ and $40^{\circ}$, was the widest among them. The reason was that the lattice distortion, which was caused by the vanadium solidification in $\alpha^{\prime}$ phase during the martensitic transformation process, was much more severely compared to $850^{\circ} \mathrm{C}$ and $950^{\circ} \mathrm{C}$. It indicated the change of lattice parameter of $\alpha^{\prime}$ phase with changing the width of diffraction peak. Therefore, the lattice parameter of $\alpha$ ' phase, which treated at different temperatures, could be obtained by analyzing the width of diffraction peak.

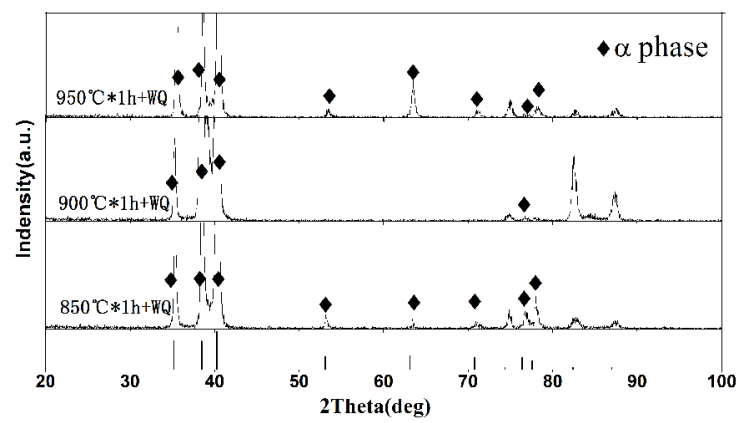

Figure 2. The XRD profiles with different heat treatment temperature. 


\subsection{Elastic properties}

Based on the generalized Hooke's law, a linear relationship exists between two tensors, i.e. stress $(\sigma)$ and strain $(\varepsilon)$. Thus a proportional elastic stiffness $\mathrm{C}_{\mathrm{ij}}$ can be simply written as:

$$
\sigma_{i}=\sum_{j=1}^{6} C_{i j} \varepsilon_{j}
$$

And the elastic compliance matrices, $\left\{\mathrm{S}_{\mathrm{ij}}\right\}$, equal to $\left\{\mathrm{C}_{\mathrm{ij}}\right\}^{-1}$.

The packed hexagonal system has five independent matrix elements:

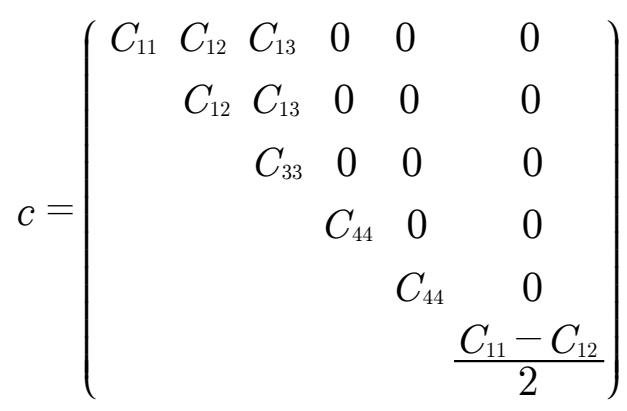

The hexagonal system mechanical stability criterion can be expressed as ${ }^{15}$ :

$$
C_{11}>0, C_{44}>0, C_{11}-C_{22}>0,\left(C_{11}+C_{22}\right) C_{33}>2 C_{13}^{2}
$$

The calculated independence $\mathrm{C}_{\mathrm{ij}}$ values of singlecrystal for the $\alpha^{\prime}$ phase formed at different heat treatment temperature were summarized in Tab.3. And the values of calculated elastic constants satisfied the above corresponding criteria, indicating that all of the $\alpha^{\prime}$ phase had elastically stable structures.

The quotient of shear modulus $(\mathrm{G})$ to the bulk modulus $(\mathrm{K}), \mathrm{G} / \mathrm{K}$, can be considered as an indication of the extent of fraction range in metals. A low value and a high value of $\mathrm{G} / \mathrm{K}$ are associated with ductility and brittleness ${ }^{15}$, respectively. As shown in Tab.4, the $\mathrm{G} / \mathrm{K}$ values were $0.397,0.408$ and 0.415 for the $\alpha^{\prime}$ phase from different heat treatment temperature, respectively. This suggested that the brittleness property was increased with the heat treatment temperature increases. This was consistent with the results of the subsequent mechanical performance.

Young's modulus and Poisson's ratio can be calculated by the following formula ${ }^{15}$ :

$$
E=\frac{9 K G}{3 K+G} \quad v=\frac{3 K-2 G}{2(3 K+G)}
$$

The elastic modulus anisotropy parameter $A_{G}$ can be calculated from the following equation ${ }^{15}$ :

$$
A_{G}=\left(G_{V}-G_{R}\right) /\left(G_{V}+G_{R}\right)
$$

Where the subscripts $\mathrm{V}$ and $\mathrm{R}$ indicate the Voigt and Reuses averages. The Young's modulus (E), Poisson's ratio $(v)$ and anisotropy parameter $\left(\mathrm{A}_{\mathrm{G}}\right)$ can be calculated by equation (4) and (5), as shown in Tab.4. It was the largest of the three that the elastic modulus anisotropy of $\alpha^{\prime}$ phase treated at $850^{\circ} \mathrm{C}$, and the anisotropy was the weakest among them when the $\alpha^{\prime}$ phase treated at $950{ }^{\circ} \mathrm{C}$. With increasing the heat treatment temperature, the $\mathrm{A}_{\mathrm{G}}$ value decreased from $1.3 \%$ to $0.8 \%$. The results demonstrated that the elastic modulus anisotropy of $\alpha^{\prime}$ phase was decreased gradually with the heat treatment temperature increasing.

The direction cosine of the three crystal directions [100], [010], [001] was used to represent the Young's modulus in any direction. Set $l_{1}, l_{2}$, and $l_{3}$ as the cosine of the angle between a direction in the space and the direction of crystal principal axis. The Young's modulus values $\mathrm{E}$ in either direction of space size were only with the $l_{1}, l_{2}$, and $l_{3}$, and the specific expression was as follows:

$1 / E=S_{11}\left(1-l_{3}^{2}\right)^{2}+S_{33} l_{3}^{4}+\left(S_{44}+2 S_{13}\right)\left(1-l_{3}^{2}\right) l_{3}^{2}$

And then used the formula (6) to calculate the elastic modulus of the four-dimensional image, the diagram was shown in Fig. 3. The elastic modulus of $\alpha^{\prime}$ phase after quenching at $850^{\circ} \mathrm{C}$ in the $\mathrm{Z}$-axis direction was $146.5 \mathrm{GPa}$, the value was $107 \mathrm{GPa}$ in the $\mathrm{X}$-axis and $\mathrm{Y}$-axis direction, and the difference value (D-value) was 39.5GPa (Fig. 3 (a1 a2)).

Table 3. Calculated elastic stiffness $\left(C_{i j}\right)$ of $\alpha^{\prime}$ phase from GGA.

\begin{tabular}{lcccccc}
\hline Phase & $\mathrm{C}_{11}$ & $\mathrm{C}_{12}$ & $\mathrm{C}_{13}$ & $\mathrm{C}_{22}$ & $\mathrm{C}_{33}$ & $\mathrm{C}_{44}$ \\
\hline$\alpha^{\prime}\left(850^{\circ} \mathrm{C} / 1 \mathrm{~h}+\mathrm{WQ}\right)$ & 162.3 & 88.9 & 70.4 & 162.3 & 186.0 & 43.2 \\
$\alpha^{\prime}\left(900^{\circ} \mathrm{C} / 1 \mathrm{~h}+\mathrm{WQ}\right)$ & 163.5 & 87.6 & 68.1 & 163.5 & 183.2 & 43.2 \\
$\alpha^{\prime}\left(950^{\circ} \mathrm{C} / 1 \mathrm{~h}+\mathrm{WQ}\right)$ & 172.0 & 86.0 & 71.6 & 172.0 & 190.0 & 43.0 \\
\hline
\end{tabular}


Table 4. Voigt (index $V$ ), Reuss (index $R$ ), and averaged macroscopic voigt-Reuss-Hill (VRH) modulus for the polycrystalline $\alpha$ ' phase; all in Gpa except for $v$ (dimensionless), $\mathrm{G} / \mathrm{K}$ and $\mathrm{A}_{\mathrm{G}}$.

\begin{tabular}{lcccccccccc}
\hline Phase & $\mathrm{K}_{\mathrm{V}}$ & $\mathrm{K}_{\mathrm{R}}$ & $\mathrm{K}$ & $\mathrm{G}_{\mathrm{V}}$ & $\mathrm{G}_{\mathrm{R}}$ & $\mathrm{G}$ & $\mathrm{E}$ & $v$ & $\mathrm{G} / \mathrm{K}$ & $\mathrm{A}_{\mathrm{G}}$ \\
\hline$\alpha^{\prime}\left(850^{\circ} \mathrm{C} / 1 \mathrm{~h}+\mathrm{WQ}\right)$ & 107.8 & 107.8 & 107.8 & 43.3 & 42.2 & 42.8 & 113.3 & 0.325 & 0.397 & $1.3 \%$ \\
$\alpha^{\prime}\left(900^{\circ} \mathrm{C} / 1 \mathrm{~h}+\mathrm{WQ}\right)$ & 106.5 & 106.5 & 106.5 & 44.0 & 43.0 & 43.5 & 114.9 & 0.320 & 0.408 & $1.1 \%$ \\
$\alpha^{\prime}\left(950^{\circ} \mathrm{C} / 1 \mathrm{~h}+\mathrm{WQ}\right)$ & 110.2 & 110.2 & 110.2 & 46.1 & 45.4 & 45.8 & 120.6 & 0.318 & 0.415 & $0.8 \%$ \\
\hline
\end{tabular}

The $\mathrm{D}$-value between the $\mathrm{Z}$-axis and the $\mathrm{X}$-axis and $\mathrm{Y}$-axis directions at $900^{\circ} \mathrm{C}$ and $950^{\circ} \mathrm{C}$ was $36.1 \mathrm{GPa}$ (Fig. 3 (b1 b2)) and $29.2 \mathrm{GPa}$ (Fig. 3 (c1 $\sim \mathrm{c} 2)$ ), respectively. It concluded that the value of elastic modulus of the $\mathrm{Z}$-axis was higher than that of the $\mathrm{X}$-axis and the $\mathrm{Y}$-axis. With increasing the quenching temperature, the $\mathrm{D}$-values among the $\mathrm{Z}$-axis, the $\mathrm{X}$-axis and Y-axis directions were reduced gradually, and the elastic modulus anisotropy was weakened. These results were also agreed with the experiment results of the elastic modulus anisotropy of macroscopic Ti-6Al-4V alloy, as shown in Fig. 4. As shown in Tab. 5 , after treating at $850^{\circ} \mathrm{C}$, the D-value between the tensile elastic modulus and the compressive elastic modulus of the Ti-6Al-4V was the maximum value, 3.96GPa. With the solid solution and quenching temperature increasing, the D-values were reduced from 3.96GPa to 2.10 $\mathrm{GPa}$. This was also the same as the change of the anisotropy elastic modulus of $\alpha^{\prime}$ phase, as shown in Fig. 3. It could be seen from the quenched microstructure of Ti-6Al-4V (Fig. 1), with increasing the solution quenching temperature, the content of $\alpha^{\prime}$ phase gradually increased. Therefore, the anisotropy elastic modulus of $\alpha^{\prime}$ phase was the key factor to affect the mechanical anisotropy of the material. With the content of $\alpha^{\prime}$ phase increasing, the effect became much more obvious. Controlling the anisotropy of the mechanical properties of $\alpha^{\prime}$ phase could control the anisotropy of the mechanical properties of the macroscopic alloy.

\subsection{Fracture surface}

Fig.5 shows the fracture surfaces of tensile samples after solution treatment and water quenching from $850^{\circ} \mathrm{C}, 900^{\circ} \mathrm{C}$ and $950^{\circ} \mathrm{C}$. The samples, which treated at $850^{\circ} \mathrm{C}$ and $900^{\circ} \mathrm{C}$, exhibited fracture surfaces with clear dimples, indicative of ductile fracture. The entire fracture surface was covered by equiaxed dimples. Compared to the samples treated at $850^{\circ} \mathrm{C}$, smaller and shallower dimples were presented in the samples treated at $900^{\circ} \mathrm{C}$. However, when the heat treatment temperature increased to $950^{\circ} \mathrm{C}$, as shown in Fig. 5 (c), the fracture mode was changed. The fracture surface contained substantial tearing ridges, cleavage facets and few dimples, which showed evidence of that quasi-cleavage fracture and intergranular fracture was main fracture modes. Moreover,
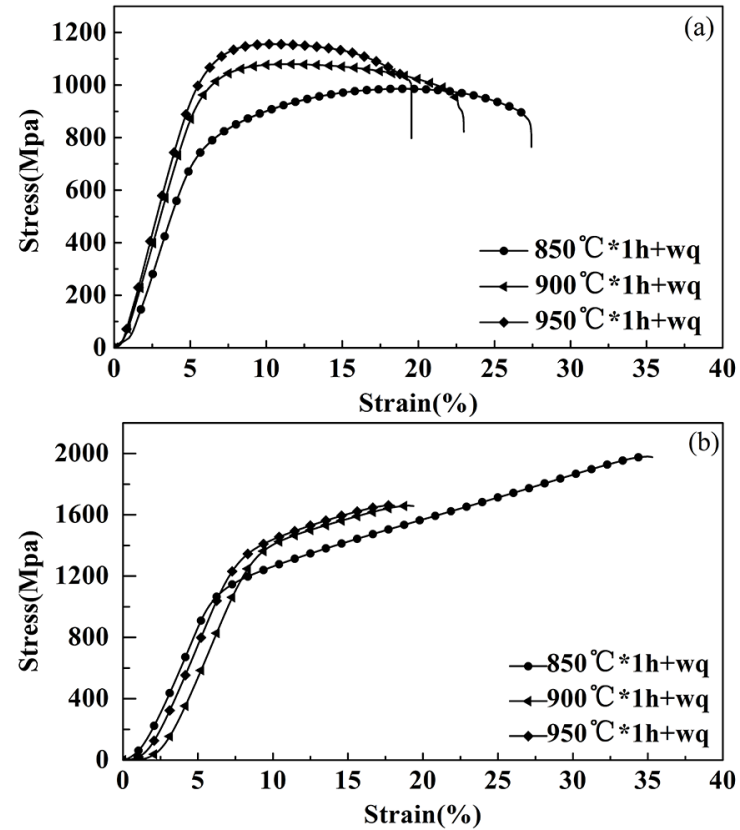

Figure 3. The four-dimensional diagrams of the Young's modulus of $\alpha^{\prime}$ phase with different heat treatment temperature: $\left(a_{1}\right)$ Four-dimensional diagrams and $\left(a_{2}\right)$ plane projections of Young's modulus of $\alpha^{\prime}$ phase after quenching at $850^{\circ} \mathrm{C} ;\left(\mathrm{b}_{1}\right)$ Four-dimensional diagrams and $\left(\mathrm{b}_{2}\right)$ plane projections of Young's modulus of $\alpha$ ' phase after quenching at $900^{\circ} \mathrm{C} ;\left(\mathrm{c}_{1}\right)$ Four-dimensional diagrams and $\left(\mathrm{c}_{2}\right)$ plane projections of Young's modulus of $\alpha^{\prime}$ phase after quenching at $900^{\circ} \mathrm{C}$.

the small cracks and voids (Fig. 5 (d)) were found in the grain boundary. The formation of the cracks was related to the grain coarsening behavior and the martensitic transformation behavior, which weakened the compatible deformation capability.

From what had been discussed above, it concluded that with increasing the solution treatment and water quenching temperature, it weakened the elastic modulus anisotropy of $\alpha^{\prime}$ phase and increased the content of $\alpha^{\prime}$ phase. It obviously influences the elastic modulus anisotropy of macroscopic Ti$6 \mathrm{Al}-4 \mathrm{~V}$ alloys. And with the content of $\alpha^{\prime}$ phase increasing, the effect became much more obvious. If the martensitic transformation process could be controlled, it will provide a promising method to precisely control the size of Ti-6Al-4V alloy sheet during the deformation process. 

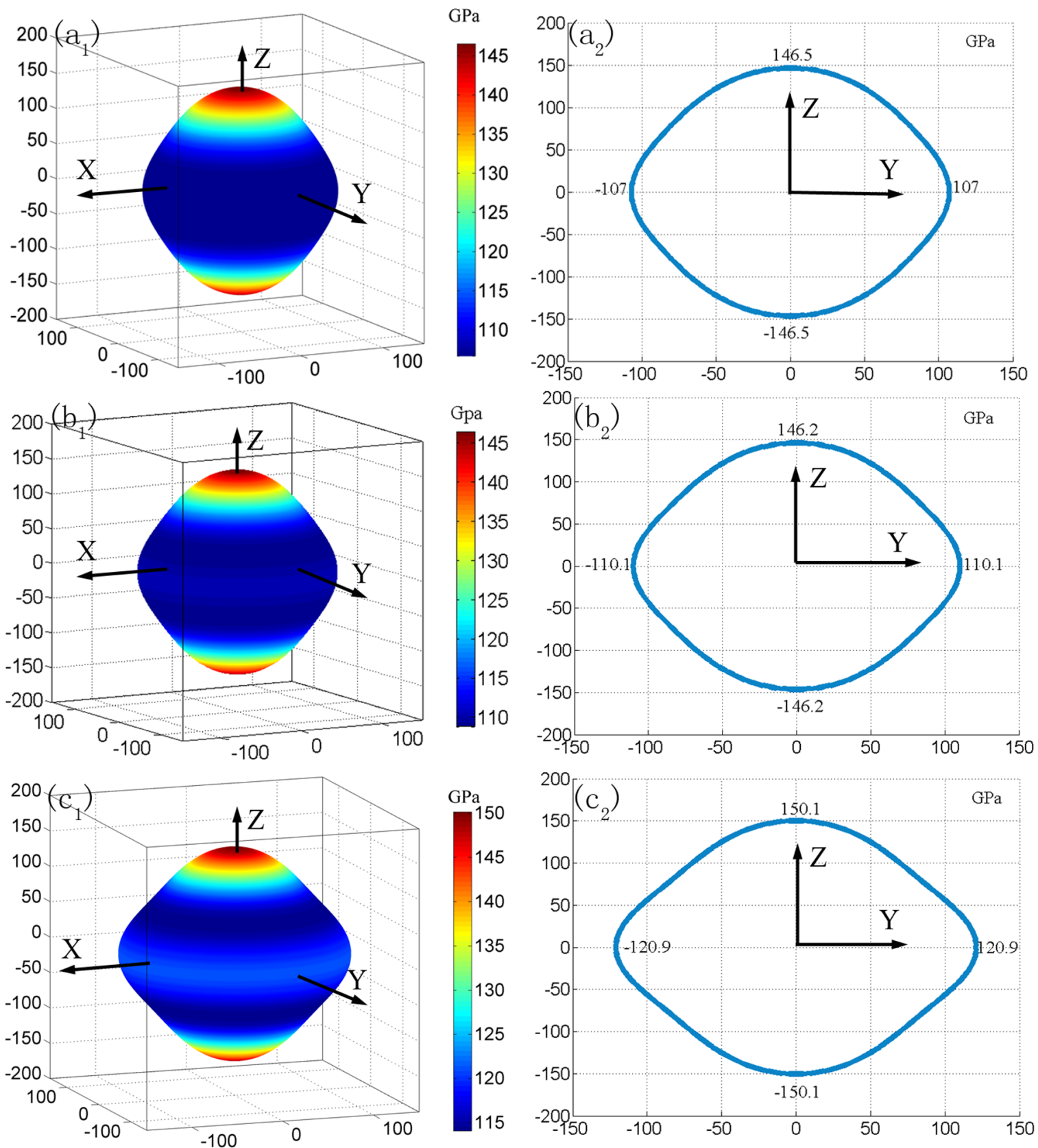

Figure 4. Tensile (a) and compressive (b) properties of Ti-6Al-4V alloy with different heat treatment temperature.

Table 5. The tensile and compressive elastic modulus for the polycrystalline material quenched from different temperature.

\begin{tabular}{lccc}
\hline Heat treatment process & Tensile elastic modulus (Gpa) & $\begin{array}{c}\text { Compressive elastic modulus } \\
(\mathrm{Gpa})\end{array}$ & $\begin{array}{c}\mid \mathrm{D} \text {-value } \\
(\mathrm{Gpa})\end{array}$ \\
\hline $850^{\circ} \mathrm{C} / 1 \mathrm{~h}+\mathrm{WQ}$ & 13.46 & 17.42 & 3.96 \\
$900^{\circ} \mathrm{C} / 1 \mathrm{~h}+\mathrm{WQ}$ & 17.30 & 14.16 & 3.14 \\
$950^{\circ} \mathrm{C} / 1 \mathrm{~h}+\mathrm{WQ}$ & 18.80 & 16.70 & 2.10 \\
\hline
\end{tabular}



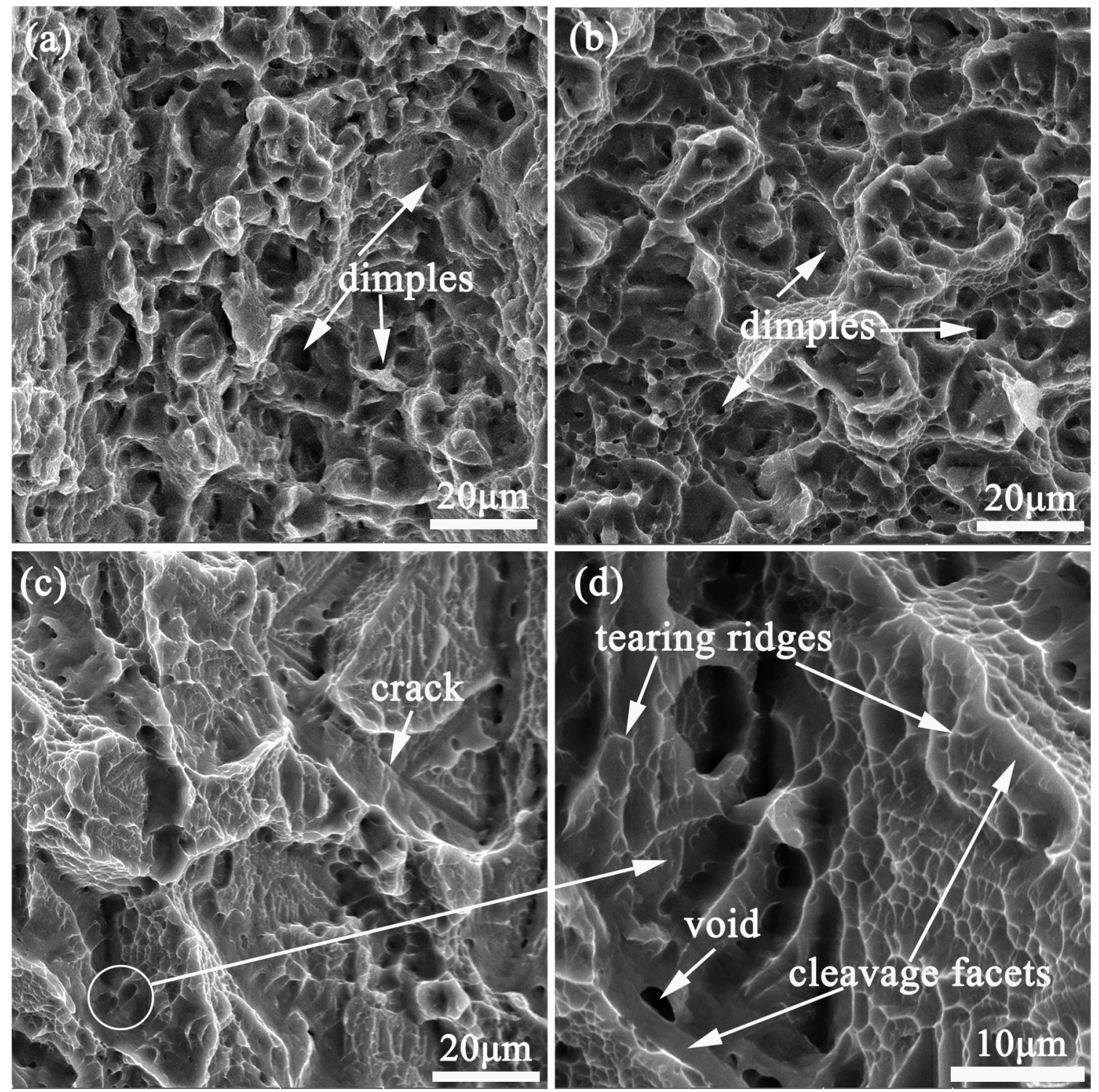

Figure 5. SEM images of tensile fracture surface of the Ti-6Al-4V alloys with different heat treatment temperature tested at room temperature: (a) $850^{\circ} \mathrm{C} / 1 \mathrm{~h}+\mathrm{WQ}$; (b) $900^{\circ} \mathrm{C} / 1 \mathrm{~h}+\mathrm{WQ}$; (c) $950^{\circ} \mathrm{C} / 1 \mathrm{~h}+\mathrm{WQ}$; (d) zoom in of image (c).

\section{Conclusions}

With increasing the solution treatment and water quenching temperature, the crystal structure parameters of $\alpha^{\prime}$ phase in Ti-6Al-4V alloy were changed. Based on the changed lattice parameter of $\alpha^{\prime}$ phase, with increasing the solution treatment and water quenching temperature, the anisotropy was gradually weakened, which was agree with the experimental mechanical performance testing results. And with the content of $\alpha^{\prime}$ phase increasing, it had much more effect on the elastic modulus anisotropy of macroscopic alloy. It concluded that the elastic modulus anisotropy of macroscopic Ti-6Al-4V alloys could be controlled by the characteristic of $\alpha^{\prime}$ phase.

\section{Acknowledgements}

This work was supported by the Yunnan Province Science Youth Experts Fund [2016FD033]. 


\section{References}

1. Galarraga H, Warren RJ, Lados DA, Dehoff RR, Kirka MM, Nandwana P. Effects of heat treatments on microstructure and properties of Ti-6Al-4V ELI alloy fabricated by electron beam melting (EBM). Materials Science and Engineering: $A$. 2017;685:417-428.

2. Yao J, Suo T, Zhang S, Zhao F, Wang H, Liu J, et al. Influence of heat-treatment on the dynamic behavior of 3D laser-deposited Ti-6Al-4V alloy. Materials Science and Engineering: $A$. 2016;677:153-162.

3. de Formanoir C, Michotte S, Rigo O, Germain L, Godet S. Electron beam melted Ti-6Al-4V: Microstructure, texture and mechanical behavior of the as-built and heat-treated material. Materials Science and Engineering: A. 2016;652:105-119.

4. Wang M, Wu Y, Lu S, Chen T, Zhao Y, Chen H, et al. Fabrication and characterization of selective laser melting printed Ti-6Al$4 \mathrm{~V}$ alloys subjected to heat treatment for customized implants design. Progress in Natural Science: Materials International. 2016;26(6):671-677.

5. Velay V, Matsumoto H, Vidal V, Chiba A. Behavior modeling and microstructural evolutions of $\mathrm{Ti}-6 \mathrm{Al}-4 \mathrm{~V}$ alloy under hot forming conditions. International Journal of Mechanical Sciences. 2016;108-109:1-13.

6. Yang J, Yu H, Yin J, Gao M, Wang Z, Zeng X. Formation and control of martensite in Ti-6Al-4V alloy produced by selective laser melting. Materials \& Design. 2016;108:308-318.

7. Mantani Y, Tajima M. Phase transformation of quenched $\alpha$ " martensite by aging in Ti-Nb alloys. Materials Science and Engineering: A. 2006;438-440:315-319.
8. Ahmed T, Rack HJ. Phase transformations during cooling in $\alpha+\beta$ titanium alloys. Materials Science and Engineering: $A$. 1998;243(1-2):206-211.

9. Kherrouba N, Bouabdallah M, Badji R, Carron D, Amir M. Beta to alpha transformation kinetics and microstructure of Ti6Al-4V alloy during continuous cooling. Materials Chemistry and Physics. 2016;181:462-469.

10. Tan X, Kok Y, Wei QT, Tan YJ, Descoins M, Mangelinck D, et al. Revealing martensitic transformation and $\alpha / \beta$ interface evolution in electron beam melting three-dimensional-printed Ti-6Al-4V. Scientific Reports. 2016;6:26039.

11. Huang L, Chen Y, Kong F, Xu L, Xiao S. Direct rolling of Ti-6Al-4V-0.1B alloy sheets in the $\beta$ phase region. Materials Science and Engineering: A. 2013;577:1-8.

12. Zhang ZX, Qu SJ, Feng AH, Shen J, Chen DL. Hot deformation behavior of Ti-6Al-4V alloy: Effect of initial microstructure. Journal of Alloys and Compounds. 2017;718:170-181.

13. Obasi GC, Birosca S, Leo Prakash DG, Quinta da Fonseca J, Preuss M. The influence of rolling temperature on texture evolution and variant selection during $\alpha \rightarrow \beta \rightarrow \alpha$ phase transformation in Ti-6Al-4V. Acta Materialia. 2012;60(17):6013-6024.

14. Zeng L, Bieler TR. Effects of working, heat treatment, and aging on microstructural evolution and crystallographic texture of $\alpha$, $\alpha^{\prime}, \alpha^{\prime \prime}$ and $\beta$ phases in Ti-6Al-4V wire. Materials Science and Engineering: A. 2005;392(1-2):403-414.

15. Zhou W, Liu L, Li B, Wu P, Song Q. Structural, elastic and electronic properties of intermetallics in the Pt-Sn system: A density functional investigation. Computational Materials Science. 2009;46(4):921-931. 